\title{
WHEN SHOULD CLEARANCE OF THE HEPATODUODENAL LIGAMENT (STATION 12) DURING RADICAL RESECTION FOR GASTRIC CANCER BE PERFORMED
}

\author{
I. Negoi ${ }^{1,2}$, S. Păun ${ }^{1,2}$, S. Hostiuc ${ }^{1,3}$, A. Runcanu ${ }^{2}$, Ruxandra Irina Negoi ${ }^{1}$, M. Beuran ${ }^{1,2}$ \\ ${ }^{1}$ The University of Medicine and Pharmacy "Carol Davila", Bucharest, Romania \\ ${ }^{2}$ The Emergency Hospital of Bucharest, Romania \\ ${ }^{3}$ The National Institute of Legal Medicine Mina Minovici, Romania \\ Corresponding author: Ionuț Negoi \\ Phone no. 0040215992308 \\ E-mail: negoiionut@gmail.com
}

\begin{abstract}
In Western countries gastric cancer continues to remain a biologically aggressive tumor, with poor long-term oncological outcomes. In Romania, the estimated gastric cancer was the fifth cause of oncological death in men and the eighth cause of oncological death in women in 2012.The objective of the study is to detail when should the hepatoduodenal ligament (station 12) be cleared surgically as a part of D2 dissection during radical gastrectomy. We have performed a review of the English language literature using PubMed/Medline library. As keywords we used a combination of the following terms: 'gastrectomy', 'stomach', 'cancer', and 'lymphadenectomy'. According to the Japanese Gastric Cancer Association, the hepatoduodenal ligament includes the lymph nodes station 12, which are further divided in $12 a$-along left side of the proper hepatic artery, $12 b-$ right side of the ligament and posterior to the common bile duct, and $12 p$-posterior to the portal vein. For middle and lower third gastric tumors, station 12 a represents the N2 tier, while for upper third gastric tumors, it represents the $N 3$ tier. Lymph nodes $12 b$ and $12 p$ represent $N 3$, irrespective of the tumor location. For middle and lower third gastric tumors the clearance of the lymph nodes surrounding the proper hepatic artery is a part of the D2 dissection. Dissection of the lymph nodes surrounding the proper hepatic artery is a component of the D2 spleen and pancreas preserving lymphadenectomy, for lesions which extend further than submucosa.
\end{abstract}

Keywords: gastric cancer; lymphadenectomy; hepatoduodenal ligament; D2 dissection

\section{Introduction}

In Romania, the estimated gastric cancer was the fifth cause of oncological death in men (2711 and 2217 cases) and the eighth cause of oncological death in women in 2012 (1364 and 1149 cases) [1]. Worldwide the gastric cancer rates decreased significantly during the latest years, especially due to dietary changes, such as food refrigeration, an increase in fresh fruits and vegetables intake, and a decrease in salted and preserved food [2]. On the other hand, the incidence of esophagogastric junction cancer increased sixfold during the last three decades in the Western countries, while it remained constant in the Eastern countries [3, 4]. Nevertheless, starting with the 7 th edition of the TNM staging, tumors located in the esophagogastric junction are staged similar with the esophageal adenocarcinoma [5]. 
Excepting the Eastern countries, where screening is used, the majority of patients with malignant tumors of the stomach are diagnosed in advanced stages of their disease, $60 \%-90 \%$ of the tumors penetrating the serosa and at least $50 \%$ having lymph nodes involvement, with poor results regarding the long-term survival, even after potentially curative resections [6].

The biology of the gastric cancer continues to be aggressive, even after an $\mathrm{R} 0$ resection, the recurrence occurring in almost half of the patients, usually within the first two years [6]. The 5-year survival rate of patients with stage $\mathrm{Ib}$ undifferentiated adenocarcinoma is $84 \%$, with a 5 -year cumulative recurrence rate of $12.8 \%$ [7]. The current curative-intent gastric resection necessitates R0 resection with concurrent extended D2 lymphadenectomy [8]. A local, regional and national audit regarding the quality of the resection compared with postoperative morbidity and mortality in patients with gastric cancer is mandatory to improve short and longterm results [9].

The objective of this research is to detail when the hepatoduodenal ligament (station 12) should be surgically cleared as a part of D2 dissection during radical gastrectomy.

\section{Materials and methods}

We have performed a review of the English language literature using PubMed/Medline library. As a keywords we have used a combination of the following terms: 'gastrectomy', 'stomach', 'cancer', and 'lymphadenectomy'.

\section{Discussions}

\section{Surgical anatomy of the hepatoduodenal ligament}

The hepatoduodenal ligament is a peritoneal structure, component of the lesser omentum, containing the portal vein, the proper hepatic artery and the common bile duct. The right gastric artery branches off the proper hepatic artery in $53 \%$, the bifurcation area of the common hepatic artery in $20 \%$, the left hepatic artery in $15 \%$, the gastroduodenal artery in $8 \%$, the common hepatic artery in $4 \%$ [10]. The left gastric vein drains into the main portal vein in $65 \%$ of cases [11]. According to the Japanese Gastric Cancer Association, the hepatoduodenal ligament includes the lymph nodes station 12, which are further divided in $12 \mathrm{a}$ - along left side of the proper hepatic artery, $12 b$ - right side of the ligament and posterior to the common bile duct, and $12 \mathrm{p}$ - posterior to the portal vein. The proper hepatic artery lymph nodes are located below the confluence of the right and left hepatic ducts and superior to the pancreatic margin [12].

\section{Extent of the gastric resection}

The resection margin should be larger than 3 $\mathrm{cm}$ in tumors with an expansive growth pattern and larger than $5 \mathrm{~cm}$ in infiltrative tumors [12]. For tumors which invade the esophagus, the 5 $\mathrm{cm}$ rule is not mandatory, but the proximal transection margin should be always verified by frozen-section analysis [12].

In cases of locally advanced $\mathrm{T} 4 \mathrm{~b}$ gastric tumors, which invade surrounding organs, there is still a survival benefit for surgically resected patients. The analysis of 2208 patients from 7 Italian centers, with curative resection for gastric cancer included 206 patients with T4b tumors [13]. This subgroup of patients presented a mortality, morbidity and 5-year survival rate of $3.6 \%, 33.9 \%$ and $27.2 \%$, respectively [13].

\section{Dissection of the station 12}

The seventh edition of TNM staging system proposed by American Joint Committee on Cancer (AJCC) and International Union Against Cancer (UICC) and published in 2010 defines the $\mathrm{N}$ stage according to the number of involved lymphnodes: pN1 (1 to 2), pN2 (3 to 6), pN3 (7 or more) [14]. The latest version of the Japanese Staging System for gastric carcinoma was published in 1998 [15]. This thorough classification defines 18 lymph node stations, stratified into three tiers (N1 to N3), according to their anatomic relations with the primary tumor. Usually the perigastric lymph nodes (stations $1-6$ ) are classified as N1, stations 7 12 as N2, and paraaortic (station 16) lymph nodes as N3. Nevertheless, some perigastric nodes are not regarded as involved regional nodes in specific tumor locations, but as distant metastasis [16]. The explanation for this is that their involvement for some specific tumor 
locations is very rare, and when they do occur the prognosis is very poor. This is the case of left paracardial lymph nodes (station 2) in antral tumors. The lymph nodes around the proper hepatic artery (12a) and superior mesenteric vein $(14 \mathrm{v})$ are common sites of involvement for lower gastric cancers, their dissection being associated with increased survival, and are classified as $\mathrm{N} 2$ [16].
According to the Japanese Gastric Cancer treatment guideline published in 2011 , the D2 lymphadenectomy is indicated in $\mathrm{N}+$ and/or T2T4 tumors, and includes dissection of $12 \mathrm{a}$ lymph nodes, in total and distal gastrectomy [12].

\begin{tabular}{|c|c|c|c|c|}
\hline Study/Location & Outcome & $\begin{array}{c}\text { D1 } \\
\text { group }\end{array}$ & $\begin{array}{c}\mathrm{D} 2 \\
\text { group }\end{array}$ & $\begin{array}{l}\text { Statistical } \\
\text { significance }\end{array}$ \\
\hline \multirow{10}{*}{$\begin{array}{c}\text { Dutch gastric Cancer } \\
\text { Trial/ Netherlands } \\
{[18,19]}\end{array}$} & Number of patients & 380 & 331 & \\
\hline & Postoperative mortality & $4 \%$ & $10 \%$ & $\mathrm{P}=0.0004$ \\
\hline & Postoperative morbidity & $25 \%$ & $43 \%$ & $\mathrm{P}<0.001$ \\
\hline & Five-year overall survival & $45 \%$ & $47 \%$ & $\mathrm{P}=\mathrm{ns}$ \\
\hline & 11-year overall survival & $30 \%$ & $35 \%$ & $\mathrm{P}=\mathrm{ns}$ \\
\hline & 15-year overall survival & $21 \%$ & $29 \%$ & $\mathrm{P}=\mathrm{ns}$ \\
\hline & 15-year gastric cancer specific death & $48 \%$ & $37 \%$ & $\mathrm{P}=0.01$ \\
\hline & 15-year local recurrence & $22 \%$ & $12 \%$ & \multirow{3}{*}{$\mathrm{P}=0.015$} \\
\hline & 15-year regional recurrence & $19 \%$ & $13 \%$ & \\
\hline & 15-year liver metastasis & $17 \%$ & $11 \%$ & \\
\hline \multirow{4}{*}{$\begin{array}{l}\text { Medical Research } \\
\text { Council Trial/United } \\
\text { Kingdom }[20,21]\end{array}$} & Number of patients & 200 & 200 & \\
\hline & Postoperative mortality & $6.5 \%$ & $13 \%$ & $\mathrm{P}<0.04$ \\
\hline & Postoperative morbidity & $28 \%$ & $46 \%$ & $\mathrm{P}<0.001$ \\
\hline & Five-year overall survival & $35 \%$ & $33 \%$ & $\mathrm{P}=\mathrm{ns}$ \\
\hline \multirow{4}{*}{$\begin{array}{c}\text { Italian Gastric Cancer } \\
\text { Study Group/Italy } \\
{[22-24]}\end{array}$} & Number of patients & 133 & 134 & \\
\hline & Postoperative mortality & $3 \%$ & $2.2 \%$ & $\mathrm{P}=\mathrm{ns}$ \\
\hline & Postoperative morbidity & $12 \%$ & $17.9 \%$ & $\mathrm{P}=\mathrm{ns}$ \\
\hline & Five-year overall survival & $66.5 \%$ & $64.2 \%$ & $\mathrm{P}=\mathrm{ns}$ \\
\hline \multirow{4}{*}{$\begin{array}{l}\text { Wu et al./Taiwan [25] } \\
\text { (D1 versus D3) }\end{array}$} & Number of patients & 110 & 111 & \\
\hline & Postoperative mortality & $0 \%$ & $0 \%$ & $\mathrm{P}=\mathrm{ns}$ \\
\hline & Postoperative morbidity & $10.1 \%$ & $17.1 \%$ & $\mathrm{P}=0.012$ \\
\hline & Five-year overall survival & $53 \%$ & $59.5 \%$ & $\mathrm{P}=0.041$ \\
\hline
\end{tabular}

Table 1 - Randomized Control Trials comparing D1 with D2/D3 lymphadenectomy in patients with gastric cancer.

In Table 1 the main evidence comparing D1 with D2 lymphadenectomy in patients with gastric cancer can be observed.

For middle and lower third gastric tumors, station 12 a represents the $\mathrm{N} 2$ tier, while for the upper third gastric tumors, it represents the N3 tier. Lymph nodes $12 \mathrm{~b}$ and $12 \mathrm{p}$ represent N3, irrespective of the tumor location. The reported incidence of cancer dissemination into the station 12 lymph nodes was between $2.9 \%$ - 22\% [2628, 20]. According to Maruyama et al. the incidence of station 12 involvement was $8 \%, 2 \%$ and $1 \%$ in cancers of the lower, middle and upper third of the stomach, respectively [28]. The reported 5-year survival rate in patients with positive station 12 lymph nodes was 9\% [28].

\section{Conclusions}

Dissection of the lymph nodes surrounding the proper hepatic artery is a component of the D2 spleen and pancreas preserving lymphadenectomy, for lesions which extend further than the submucosa. 


\section{References}

[1]Organisation WH. GLOBOCAN 2012 (IARC) Section of Cancer Surveillance 2012. Accessed $15 / 2 / 2016$.

[2]Jemal A, Bray F, Center MM, Ferlay J, Ward E, Forman D. Global cancer statistics. CA: a cancer journal for clinicians. 2011;61(2):69-90. doi:10.3322/caac.20107.

[3]Keeney S, Bauer TL. Epidemiology of adenocarcinoma of the esophagogastric junction. Surgical oncology clinics of North America. 2006;15(4):687-96. doi:10.1016/j.soc.2006.07.014.

[4]Hasegawa S, Yoshikawa T. Adenocarcinoma of the esophagogastric junction: incidence, characteristics, and treatment strategies. Gastric cancer : official journal of the International Gastric Cancer Association and the Japanese Gastric Cancer Association. 2010;13(2):63-73. doi:10.1007/s10120010-0555-2.

[5]Graziosi L, Marino E, Cavazzoni E, Donini A. Prognostic value of the seventh AJCC/UICC TNM classification of non-cardia gastric cancer. World Journal of Surgical Oncology. 2013;11:103doi:10.1186/1477-7819-11-103.

[6]D'Angelica M, Gonen M, Brennan MF, Turnbull AD, Bains M, Karpeh MS. Patterns of Initial Recurrence in Completely Resected Gastric Adenocarcinoma. Annals of Surgery. 2004;240(5):808-16.

doi:10.1097/01.sla.0000143245.28656.15.

[7]Yokoyama T, Kamada K, Tsurui Y, Kashizuka H, Okano E, Ogawa $\mathrm{S}$ et al. Clinicopathological analysis for recurrence of stage $\mathrm{Ib}$ gastric cancer (according to the second English edition of the Japanese classification of gastric carcinoma). Gastric cancer : official journal of the International Gastric Cancer Association and the Japanese Gastric Cancer Association. 2011;14(4):372-7. doi:10.1007/s10120011-0051-3.

[8]Schwarz RE. Current status of management of malignant disease: current management of gastric cancer. J Gastrointest Surg. 2015;19(4):782-8. doi:10.1007/s11605-014-2707-x.

[9]Beuran M, Negoi I, Paun S, Vartic M, Stoica B, Tănase I et al. Quality management in general surgery: a review of the literature. Journal of Acute Disease. 2014;3(4):253-7. doi:http://dx.doi.org/10.1016/S2221-6189(14)600573.

[10]Eckmann I, Krahn V. [Frequency of different sites of origin of the right gastric artery]. Anatomischer Anzeiger. 1984;155(1-5):65-70.

[11]Rebibo L, Chivot C, Fuks D, Sabbagh C, Yzet T, Regimbeau JM. Three-dimensional computed tomography analysis of the left gastric vein in a pancreatectomy. HPB (Oxford). 2012;14(6):414-21. doi:10.1111/j.1477-2574.2012.00468.x.

[12]Association. JGC. Japanese gastric cancer treatment guidelines 2010 (ver. 3). Gastric cancer : official journal of the International Gastric Cancer Association and the Japanese Gastric Cancer Association. 2011;14(2):113-23. doi:10.1007/s10120-011-0042-4.

[13]Pacelli F, Cusumano G, Rosa F, Marrelli D, Dicosmo M, Cipollari $\mathrm{C}$ et al. Multivisceral resection for locally advanced gastric cancer: an Italian multicenter observational study. JAMA surgery. 2013;148(4):353-60. doi:10.1001/2013.jamasurg.309.

[14](AJCC) AJCoC. AJCC Cancer Staging Manual. 7th Edition ed. Chicago (Ilinois): Springer; 2010.

[15]Japanese Gastric Cancer A. Japanese Classification of Gastric Carcinoma - 2nd English Edition. Gastric cancer : official journal of the International Gastric Cancer Association and the Japanese Gastric Cancer Association. 1998;1(1):1024. doi:10.1007/s101209800016.

[16] Sayegh ME, Sano T, Dexter S, Katai H, Fukagawa T, Sasako M. TNM and Japanese staging systems for gastric cancer: how do they coexist? Gastric cancer : official journal of the International Gastric Cancer Association and the Japanese Gastric Cancer Association. 2004;7(3):140-8. doi:10.1007/s10120-004-0282-7.

[17]Namieno T, Koito K, Higashi T, Sato N, Uchino J. General pattern of lymph node metastasis in early gastric carcinoma. World J Surg. 1996;20(8):9961000.

[18]Bonenkamp JJ, Hermans J, Sasako M, van de Velde CJ, Welvaart K, Songun I et al. Extended lymph-node dissection for gastric cancer. The New England journal of medicine. 1999;340(12):908-14. doi:10.1056/nejm199903253401202.

[19]Songun I, Putter H, Kranenbarg EM, Sasako M, van de Velde CJ. Surgical treatment of gastric cancer: 15-year follow-up results of the randomised nationwide Dutch D1D2 trial. The Lancet Oncology. 2010;11(5):439-49.

doi:10.1016/s14702045(10)70070-x.

[20] Cuschieri A, Weeden S, Fielding J, Bancewicz J, Craven J, Joypaul V et al. Patient survival after D1 and D2 resections for gastric cancer: long-term results of the MRC randomized surgical trial. Surgical Co-operative Group. British journal of cancer. 1999;79(9-10):1522-30. doi:10.1038/sj.bjc.6690243.

[21]Cuschieri A, Fayers P, Fielding J, Craven J, Bancewicz J, Joypaul $\mathrm{V}$ et al. Postoperative morbidity and mortality after D1 and D2 resections for gastric cancer: preliminary results of the MRC randomised controlled surgical trial. The Surgical 
Cooperative Group. Lancet (London, England). 1996;347(9007):995-9.

[22]Degiuli M, Sasako M, Calgaro M, Garino M, Rebecchi F, Mineccia $M$ et al. Morbidity and mortality after D1 and D2 gastrectomy for cancer: interim analysis of the Italian Gastric Cancer Study Group (IGCSG) randomised surgical trial. European journal of surgical oncology : the journal of the European Society of Surgical Oncology and the British Association of Surgical Oncology. 2004;30(3):303-8. doi:10.1016/j.ejso.2003.11.020.

[23]Degiuli M, Sasako M, Ponti A, Vendrame A, Tomatis M, Mazza C et al. Randomized clinical trial comparing survival after D1 or D2 gastrectomy for gastric cancer. The British journal of surgery. 2014;101(2):23-31. doi:10.1002/bjs.9345.

[24]Degiuli M, Sasako M, Ponti A. Morbidity and mortality in the Italian Gastric Cancer Study Group randomized clinical trial of D1 versus D2 resection for gastric cancer. The British journal of surgery. 2010;97(5):643-9. doi:10.1002/bjs.6936.
[25]Wu CW, Hsiung CA, Lo SS, Hsieh MC, Chen $\mathrm{JH}, \mathrm{Li}$ AF et al. Nodal dissection for patients with gastric cancer: a randomised controlled trial. The Lancet Oncology. 2006;7(4):309-15. doi:10.1016/s1470-2045(06)70623-4.

[26]Methasate A, Trakarnsanga A, Akaraviputh T, Chinsawangwathanakol V, Lohsiriwat D. Lymph node metastasis in gastric cancer: result of D2 dissection. Journal of the Medical Association of Thailand $=$ Chotmaihet thangphaet. 2010;93(3):3107.

[27]Wu LL, Liang H, Wang XN, Liu XY, Han T. [Clinical characteristics of 103 lymph node metastasis in advanced proximal gastric cancer]. Zhonghua wei chang wai ke za zhi $=$ Chinese journal of gastrointestinal surgery. 2010;13(8):590-3.

[28]Maruyama K, Gunven P, Okabayashi K, Sasako M, Kinoshita T. Lymph node metastases of gastric cancer. General pattern in 1931 patients. Ann Surg. 1989;210(5):596-602. 